\author{
Berenika Lewicka \\ Technische Universität Berlin \\ Straße des 17. Juni 135, 10623 Berlin, Germany, belewiki@campus.tu-berlin.de \\ (D) https://orcid.org/0000-0002-4091-4363 \\ Dagmara Lewicka \\ AGH University of Scicence and Technology \\ aleja Adama Mickiewicza 30, 30-059 Kraków, Poland, dagal@poczta.fm \\ (1) https://orcid.org/0000-0002-6955-7371
}

\title{
ENVIRONMENTAL RISK MANAGEMENT IN THE CONTEXT OF ENVIRONMENTAL MANAGEMENT SYSTEMS FOR AGRICULTURE BASED ON THE ISO 14001:2015 STANDARD
}

\begin{abstract}
Agriculture is a risky industry because forces beyond human control influence the quality and profitability of their activities. Farmers' incomes reveal high volatility due to product and crop price as well as catastrophic risks such as natural disasters and diseases. The following paper discusses different methods, also those not specific to EMS, and their exemplary application. An attempt has been made to answer the question of what methods of risk analysis and management are appropriate for agriculture. The goal is to identify methods which can be used in EMS for agriculture, especially in the family farmsteads. The paper is based on the latest, third edition of ISO 14001.
\end{abstract}

Keywords

risk, risk management, agriculture, family farmsteads, EMS, ISO

\section{Introduction}

According to ISO 14001, risk can be defined as effect of uncertainty. An effect is a deviation from the expected - positive or negative behavior. Uncertainty is the state, even partial, of deficiency of information related to, understanding or knowledge of, an event, its consequence, or likelihood. Risk is often characterized by a reference to potential "events" and "consequences" (as defined in ISO Guide 73:2009, 3.6.1.3), or a combination of these. Risk is often expressed in terms of a combination of the consequences of an event (including changes in circumstances) and the associated "likelihood" (as defined in ISO Guide 73:2009, 3.6.1.1) of occurrence.

In terms of environment and safety management, the term 'risk' may be defined as the most likely consequence of a hazard situation, combined with the likelihood or probability of it occurring. Usually, health, safety, and the environment are linked despite being separate disciplines [1]. The reason for this is organizational management structures. Furthermore, there are strong links among these disciplines, for example, that a single risk event may have impacts on the all above areas, albeit over differing timescales. For example, the uncontrolled air pollution has an impact on the environment, which is the decrease of air quality, and the impact on human health, which may be an increase of lung diseases.

Risk management is a relatively recent corporate function. From the very beginning, risk management has been associated with pure economics: the use of market insurance to protect individuals and companies from various losses associated with accidents [2]. Over time, environmental risk analysis has developed, which is a field of study that attempts to explain events and activities that bring risk to the environment or human health [3]. Risk management is the taking of decisions and the implementation of actions aimed at achieving an acceptable level of risk by an entity. In practice, risk management is identified with risk diagnosis and control processes, the objective of which is to intentionally ensure stable financial results and to create conditions for further development [4].

From the agricultural point of view, risk is imperfect knowledge where the probabilities of the possible outcomes are known and uncertainty when these are not known. Thus, improving risk assessment and risk management methodologies will affect resilience in agriculture and, as a consequence, leverage finance and investments [5]. This observation can also be applied in few other areas with beneficial impacts for all stakeholders. Furthermore,

https://doi.org/10.32933/Actalnnovations.33.6 • ISSN 2300-5599 • C 2019 RIC Pro-Akademia - CC BY 
countries that have risk indexes such as low social vulnerability and adequate coping capacity under control, tend to have better economic performance [6].

Regarding the environment, there are two types of environmental risk. The first is the possibility of negative deviations from corporate aims by environmental effects [7]. It is the risk which is created by the environment and may have a negative impact on a company, for example a flood or heavy rain which may destroy the crops.

The other is the possibility of negative effects on the environment, caused by the presence and activities of a company, with following compensating reactions, burden or overload of the environment [8]. To illustrate this type of risk, the example of contamination of groundwater by pesticides may be used.

The aim of this paper is to review risk management methods and to indicate which of them can be used at different stages of the process in family farms that have implemented the ISO 14001 standard.

\section{Materials and methods}

In the following analysis, the focus is primarily on the ISO 14001 standard. The overall goal of ISO 14001 is the improvement of the environment. It is the added benefit of reduced business risk and increased operating efficiencies that have brought the acceptance of the standard to what it is today. It specifies requirements that enable an organization to achieve the intended outcomes it sets for its environmental management system.

The latest, third edition of the ISO 14001 standard has been released after a relatively long period of time. The previous version was reviewed and introduced with changes in 2004 . The relatively long period of time between revisions was also influenced by the fact that the changes introduced in the standard are so significant that they cause an almost complete change in the content of the standard.

The reading of the standard clearly indicates the increase in the importance of environmental management in planning processes. Introduced new requirements in terms of understanding the organization's context and impact of interested parties in a radical way affect the perception of environmental threats from the organization as well as the environmental impact on the organization. Consideration of the interested parties at the planning point means taking the requirements of state authorities, administration or other influences that may pose a threat to the organization or provide opportunities into account.

Risk is an important part of the Environmental Management System (EMS), because it has strong impact not only on the environment, but also on a company's image and its financial performance. Standard risks and opportunities were mentioned twice in the ISO: first in the planning chapter as actions to address risks and opportunities and second in the operation chapter as emergency preparedness and response. According to ISO 14001, each risk management process consists of four successive stages: risk identification, risk assessment, risk management, monitoring and control of risks. An attempt was made to review not only environmentally specific methods of risk identification, but also risk assessment and risk management.

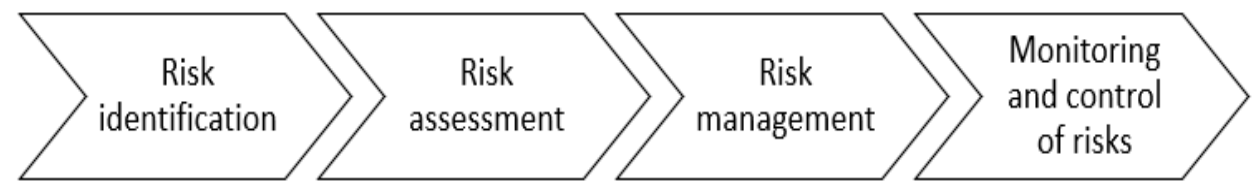

Figure 1. Risk management process

Source: Jajuga, 2007

Most of the reviewed risk assessment methods contain common elements, which include: the identification of hazards, the assessment of the likelihood of potential hazards and the losses they may cause. This applies to both the business and the environmental spheres. Regardless of which methods or strategy the company chooses, it is always necessary to collect information that will help to identify and develop an optimal methodology for risk management.

In order to achieve the objective of the study, the current literature on risk management has been reviewed. Resources available in the ScienceDirect - Elsevier database were used for the study. The search for literature on the subject was conducted according to the following keywords: risk management, ISO14001, agriculture. In the first stage of the research, risk management methods were assigned to particular stages of the risk management 
process. After that they were reviewed and examined as to whether they are appropriate for EMS and finally whether they are appropriate for risk management in agriculture. Guidance on the implementation of these methods in an organization dealing with agricultural activity is also presented.

\section{Results of the review of risk management methods}

Agriculture is associated with the pursuit of certain economic activities by a specific entity. Usually, an investment is a part of a business which is supposed to achieve the assumed goals, mainly economic. A number of activities carried out are therefore connected with making many decisions. Every economic decision includes an element of risk, which is naturally an innate part of doing business [10]. The implementation of agricultural investments within the framework of the conducted business can therefore be described as exposed to high risk due to such characteristic features as: high complexity of problems, long execution and production cycle, capital intensity, high involvement of material resources, complicated system of cooperation, a wide range of stakeholders and natural factors which are not influenced by the participants [5].

The development of a working methodology for the entire project management team is of great importance in the project risk management process. The construction of the decision-making platform will constitute a constant point of reference for all project stakeholders during the implementation of subsequent stages of the risk management process. The roles and responsibilities of risk managers, risk management costs, deadlines for action (control, monitoring), risk categories and classifications should be defined. Risk identification, as the next stage of project risk management, contributes to determining which threats may appear during the project life cycle. The identification is carried out continuously and repeatedly as a detailed description of the data already processed or in response to new situations. Risk factor identification methods usually require the contact of many people in the form of meetings of the project manager, project management team, persons responsible for a given risk factor, internal and external experts, client, investor and other stakeholders of the project. The result of individual or group workshops is usually a list of identified risk factors, which will be assessed during a qualitative and quantitative analysis to determine how to react to the risk. The consequence of the risk management process is a continuous monitoring and control process. It is a planned supervision over the entire project and risk monitoring. Both the factors disclosed in the identification process and the new ones, which were not diagnosed earlier and were disclosed during the implementation, are subject to constant observation.

Monitoring is aimed at activating planned remedial actions by introducing established reactions to a given factor. The result of iteration, i.e. the re-examination of a given event, may be: a change in the risk factor's importance status, a change in the resource responsible for the monitored factor and a modified approach to the response to its occurrence [11]. Table 1 presents risk management methods indicating those which, in the opinion of the authors, are most useful for family farms, which can be used and those whose use is not recommended. 
Table 1. Scope of using risk Management methods in the management process, $X X X$-Predominant use, $X$-Secondary use.

\begin{tabular}{|c|c|c|c|c|}
\hline & $\begin{array}{c}\text { Risk } \\
\text { identification }\end{array}$ & $\begin{array}{c}\text { Risk } \\
\text { assessment }\end{array}$ & $\begin{array}{c}\text { Risk } \\
\text { management }\end{array}$ & $\begin{array}{l}\text { Monitoring and } \\
\text { control of risks }\end{array}$ \\
\hline Analogy comparison & $\mathrm{XXX}$ & $\mathrm{X}$ & $\mathrm{X}$ & \\
\hline Assumption analysis & $\mathrm{XXX}$ & & & \\
\hline Avoidance of risk & & & & $X X X$ \\
\hline Brainstorming & $\mathrm{XXX}$ & & $\mathrm{X}$ & \\
\hline Checklists & & & $\mathrm{X}$ & $\mathrm{XXX}$ \\
\hline Crawford Slip Method (CSM) & $\mathrm{XXX}$ & & $\mathrm{X}$ & \\
\hline $\begin{array}{l}\text { Decision analysis - Expected monetary } \\
\text { value }\end{array}$ & & $X X X$ & & \\
\hline Decision Tree & & $\mathrm{XXX}$ & & \\
\hline Delphi technique & $\mathrm{XXX}$ & $\mathrm{X}$ & $\mathrm{x}$ & \\
\hline Documentation review & $X X X$ & & $\mathrm{X}$ & $\mathrm{X}$ \\
\hline Estimating relationships & & $\mathrm{XXX}$ & $\mathrm{X}$ & \\
\hline Expert interviews & $\mathrm{XXX}$ & $\mathrm{X}$ & $\mathrm{X}$ & \\
\hline Failure Mode and Effect Analysis FMEA & $\mathrm{XXX}$ & $\mathrm{X}$ & & \\
\hline Financial control of risk & & & & $\mathrm{XXX}$ \\
\hline Monte Carlo simulations & & $X X X$ & & \\
\hline Network analysis & $x$ & $X X X$ & $\mathrm{x}$ & \\
\hline Performance tracking & & & $\mathrm{X}$ & $X X X$ \\
\hline Plan evaluation & $X X X$ & & & \\
\hline Planning meetings & $x$ & $x$ & $X X X$ & \\
\hline $\begin{array}{c}\text { Program Evaluation and Review } \\
\text { Technique (PERT) }\end{array}$ & $\mathrm{X}$ & $X X X$ & & \\
\hline Project templates & & $x$ & $X X X$ & $x$ \\
\hline Rating schemes & & $\mathrm{XXX}$ & $x$ & \\
\hline Risk factors & & $X X X$ & $x$ & \\
\hline Risk practice methodology & & $\mathrm{X}$ & $X X X$ & \\
\hline Risk response matrix & & & $X X X$ & \\
\hline Risk reviews and audits & & & $x$ & $\mathrm{XXX}$ \\
\hline Sensitivity analysis & & $X X X$ & & \\
\hline SWOT analysis & $X X X$ & & $x$ & \\
\hline
\end{tabular}

\section{Predominant use in risk identification}

The method of analogy comparison shall use archived documentation previously implemented projects. Referring to such documentation, processes are being searched for solutions analogous to the current project and those applied in the past, the analyses and the results and results obtained. Despite the uniqueness of each project, it is possible to use previous experience in analogous or similar applications projects. This approach makes it possible to benefit from the valuable information retained on risks, problems, failures and successes of previous implementations in relation to the current project [12]. This method has the advantage of being applicable in a wide variety of situations, therefore it can also be used in EMS and agriculture. However, it should only be used as first step in identifying the risk, because every situation is still unique, and using only this method may result in the omission of important risk sources.

The assumption analysis consists of documentation that ensures a consistent interpretation of the design environment. Although the documentation can take many forms, the key is its consistent application. If all projects in the organization use the same structure of documentation to capture assumptions, it is much easier to interpret information in a consistent manner. The technique also includes the analysis of data collected in the documentation in order to determine the validity of each assumption. The most effective assumptions analysis will be done with multiple parties and with extensive documentation. This method may be used in EMS, when the organizations have many projects and there is the need to compare them or assume some outcomes. This is rather not useful for EMS in agriculture. However, it may be used to prepare assumptions based on previous agriculture seasons. In this way stakeholders may improve risk management with every season. 
The brainstorming method is used to obtain information from the participants of the meeting on a risk problem clearly defined by the leader in the project. Each participant has the opportunity express their opinion, which is not evaluated in relation to the value of the information. No assumption is made a rigid framework for discussion. What is important is how the greatest flow of information without stereotyping thinking about a particular issue. This leads to significant openness of the participants and expression new opinions and solutions [13]. This technique has the advantage, that it's applicable in an exceedingly wide selection of areas, consequently in EMS and agriculture. It is very beneficial, because it does enable various point of view from different employers and different experience. Ideas should be verified by experts or more experienced employers to outplace the irrelevant ones or to give them various priorities.

The Crawford Method is a clearly formulated question or a specific risk problem in a project is posed to the participants in the study. In a tenfold repetition of the questioning process, participants answer or express their opinion anonymously and in writing. The multiple posing of the same question or problem make allows for a new look at the same question or problem to be obtained. This increases the chance of revealing new information about risks that could be missed with fewer repetitions. This is useful, when there is no time or ability to discuss ideas, and just the will to collect people's thoughts. [12]. This method can be compared to brainstorming, when there is the possibility of getting more answers from various people. However over $96 \%$ of the farmsteads in the EU are family farms [14], so questionnaires does not make much sense in this situation.

The Delphi technique is based on the knowledge of experts in a given field. The opinion of all survey participants is obtained (by correspondence) by filling out a developed risk questionnaire for a given project. The aim is to obtain a common, uniform expertise of all the respondents. Participants are anonymously acquainted with the opinions of other experts in order to express their opinions in this area or to verify their views. The process is repeated several times, as appropriate [15]. This technique has the advantage that it's applicable in a wide selection of areas, therefore, also in EMS and agriculture. Process of risk identification in agriculture requests the opinion of specialists, particularly in upcoming investments or vital changes of profile.

Documentation review consists in a detailed analysis and reading of the documentation used for the implementation of the project in terms of risk identification. An overview is carried out in order to avoid omitting relevant information that may permit the identification of risk factors. The documentation under review should originate from both the client and the project implementers. The method was implemented at the time of the development of the first project documents and in the course of the creation of new ones. Documents to be submitted for review: structure of the division of labor, project fiche, contract, scope of works, documentation concerning requirements, network diagrams [12]. This method has advantage in processes, during which a lot of documentation is produced and the information included in them may be useful for risk identification. It has a wide application in EMS, however it is not advantageous for agriculture.

Expert interviews are based on the selection of a suitable expert in a given field of the project and providing him/her with specially prepared questions, in the form of a questionnaire, concerning this field. They obtain information about the risks of the project and possible threats in the case of its occurrence. It gathers knowledge about the probability and consequences of unfavorable events. It gathers information about the possibilities of preventing critical situations. It predefines how to react to risk factors. It gives the possibility to identify areas in the project that are particularly susceptible to risk [12]. The expert interview has the advantage that they are applicable in a wide variety of situations, therefore it can also be used in EMS. The identification of risk in agriculture requests the opinion of experts especially in uncommon situations, such as investments or significant changes of the profile. Therefore, this method may be very beneficial for agriculture, but not in 'everyday use'.

The Failure Mode and Effect Analysis (FMEA) is based on dividing the process or product into the smallest possible units and to identify the risk which may take place there. The FMEA methodology should already be applied in the early phase of product development (planning and development) within the product life cycle, since cost/benefit optimization is most economical in the development phase (preventive error avoidance). The later an error is discovered, the more difficult and cost-intensive its correction will be [16]. This method is rather used in developing new methods, processes or services or looking for improvement. It has a wide application in EMS, but it is rather not useful in agriculture.

Plan evaluation is based on the fact that the implementation of the project is preceded by a detailed planning and documentation Planning. It defines what is to be done, how is it to be done, when and by which participant in the project. To avoid omitting details that are relevant to the project, it is important for the efficient implementation of the project, that the actions are carried out methodologically, carefully and repeatedly. A verification of the completeness and consistency of all materials should also take place. At the same time, this is also a way to assess the error-freeness and the timeliness of the relevant data [12]. This method is used in the

https://doi.org/10.32933/Actalnnovations.33.6 • ISSN 2300-5599 • C 2019 RIC Pro-Akademia - CC BY 
project planning process and may be used in EMS. Due to the specific nature of the agriculture industry, this approach does not have a wide application.

The SWOT analysis is a directional method of risk identification in a project and in a wider context at the level of an organization. During the analysis, information is collected as a result of the questions posed: what the advantages and weaknesses in the organization are, what possibilities the project opens and what threats the project implementation poses for the organization. Conducted in the initial stage of project planning, it leads to a description of the general risks or possibilities of project implementation [17]. The SWOT analysis may be used in fact in everyday decision-making processes; therefore, it is also applicable for risk management in EMS and agriculture. Table 2 presents all the discussed methods and their relevance for EMS in agriculture for family farms.

Table 2. Summary of methods

\begin{tabular}{|c|c|}
\hline Method & Usefull for agriculture \\
\hline SWOT analysis & Yes \\
\hline Analogy comparison & Yes, with other method \\
\hline Brainstorming & Yes, results should be reviewed \\
\hline Delphi technique & Yes, for special situations, not in everyday use \\
\hline Expert interviews & Yes, for special situations, not in everyday use \\
\hline Crawford Slip Method (CSM) & May be used \\
\hline Assumption analysis & No \\
\hline Documentation review & No \\
\hline Failure Mode and Effect Analysis FMES & No \\
\hline \multicolumn{2}{|c|}{ Plan evaluation } \\
\hline
\end{tabular}

\section{Predominant use in risk assessment}

In situations where good probability estimates can be developed for the states of nature, the expected monetary value (EMV) method is a popular technique for making decisions. In general, three steps are involved in formulating a decision theory problem using the EMV method: Define the problem, identify alternatives that the decision maker may consider and identify those relevant future events that might occur and are beyond the decision maker's control. In decision theory terminology, an outcome that results from a specific decision and the occurrence of a particular state of nature is referred to as the payoff [18]. This technique may be used with success in EMS and in agriculture. If there's a negative risk, for example flood with a 10 percent probability, the impact of not getting the insurance is estimated at EUR 400,000 . For the same situation, there is big chance there will be no flood and there will be no need to pay EUR 40,000 insurance. After calculation:

$$
\begin{gathered}
10 \% \cdot-E U R 400,000=-E U R 40,000 \\
90 \% \cdot E U R 40,000=E U R 36,000
\end{gathered}
$$

It is visible, that the more beneficial solution is the second one. This method may be used in more complex situations with more outcomes. In this case it is worth drawing a decision tree to estimate all of the possibilities and their probabilities. It is applicable in EMS and consequently in agriculture.

The estimating relationship method enables the evaluation of a project, and the application of an equation to determine an appropriate contingency or risk funds budget. When using this method, the contingency funds represent the amount of funding required for work associated with unanticipated risks. The computed contingency funds requirement is usually expressed as a percentage of the baseline cost estimate. The technique is called an estimating relationship method because it uses some of the same techniques associated with cost estimating relationships (The CER method is based on the observation that costs of systems seem to correlate with design or performance variables.) used in parametric cost estimating [12]. This method is most appropriate in circumstances where a good description of a historic project and contingency fund requirements are available for several similar projects. If the required relationship for estimating risk financing is available, this method has the advantage of being quick and easy to apply. This method may be applicable in EMS, to estimate costs of various risks and to compare similar projects. It has no practical application in agriculture.

The Monte Carlo simulation uses simulation analysis to establish relative levels of risk. In many cases it is assumed that all project risks must be accounted for in the worst case. In contrary to this approach, this method takes a more holistic approach: it calculates various risks from random values from the highest and the lowest possible.

https://doi.org/10.32933/Actalnnovations.33.6 • ISSN 2300-5599 • C 2019 RIC Pro-Akademia - CC BY 
This action is repeated many times to provide a frequency distribution of total costs, reflecting the aggregate of the cost risks associated with all individual elements. Therefore, a computer with appropriate software is necessary to use this technique, as the method requires many repeated computations. This method can be used in EMS and in agriculture. With its holistic approach all possible risks may be assessed and included. By taking the flood or other natural risk as an example, it is unlikely that this will destroy $100 \%$ of the crops. Also, some risks do not occur simultaneously, or some are effects of various situations. This method may include it. Network analysis is based on the methods of arrow and nodal diagrams (also known as sequence diagrams), which graphically illustrate the logical relationships between all tasks or groups of activities in a project. The basic idea describes the relationship between tasks as an end - beginning, saying that the next task (successor) cannot start unless the task immediately preceding it (predecessor) is completed. Other relationships are end - end, beginning - beginning, beginning - end. The risk analysis is carried out, determining the probability of the occurrence of negative factors. The analysis focuses on the relationship between all tasks in the network diagram and at risk, that may exist for these tasks [12]. This method may be used in EMS, because it holistically analyses all process. It may be consequently used in agriculture, however it is not very convenient, because the process itself is relatively simple and risks usually come from the outside. It does help, however, to predict where to expect them.

Program Evaluation and Review Technique (PERT) objectives included managing schedule risk by establishing the quickest development schedule, monitoring progress and funding or applying necessary resources to maintain the schedule. The PERT method is particularly useful in managing research and development projects, where deterministic determination of activity times is generally difficult, if not impossible [19]. This approach may be used in EMS but it is inefficient for small projects, therefore it is suitable for managing large, complex projects. Due to the specific nature of agriculture, this method is rather inefficient.

Rating schemes are standardized and applied either at the project or (ideally) at the organization level. They clarify the relative magnitude in terms of impact and probability for a given risk using terms such as "high", "medium" and "low". This method uses clear definitions and the means to verify the compliance of individual risks [12]. Rating schemes are appropriate any time a qualitative analysis is conducted, therefore they might be used in EMS. On the other hand they require an up-front investment of time and management energy to establish consistent measures for probability and impact, what makes them not that easy to apply in simple processes such as agriculture.

The risk factor method is considered simple and easy to implement. First the obtained project costs should be estimated, by breaking down process into the work package level. This should include enough information to answer any question or issue about their content. A risk factor shall be made after the identification of the work package. The level of additional cost risk shell be expressed as a percentage of the original estimation and should be added to the task costs to accommodate additional work resulting from risk. After the sum of the work packages risk may estimate new project costs [12]. This technique is applicable exclusively when single datapoint assess in work package is available. The method's simplicity makes it applicable to all projects regardless of size, therefore it may be applicable in EMS in all kinds of industries.

Sensitivity analysis is a simple analytical tool which consists in examining the impact of changes in the formation of project benefits and costs, discount rate, life expectancy on its profitability level, both in financial and economic terms. This analysis is used to determine the sensitivity of profitability assessment results to changes in various variables is an important tool for reducing the risk of decisions taken in a market economy, and in particular, may concern the profitability of investment. The basis of this method is that the future cannot be predicted and with this the actual values of each variable taken into account in the investment account will deviate from these assumptions. The basic function of this analysis is to calculate the turning point, which means that the cost of the product sold equals the income [20]. This method is rather beneficial for financial end economic considerations of project; therefore, it does not find its application in EMS.

Table 3 presents all the discussed methods and their relevance for EMS in agriculture for family farms. 
Table 3. Summary of methods

\begin{tabular}{|c|c|}
\hline Method & Useful for agriculture \\
\hline Risk factors & Yes, applicable for simple processes \\
\hline Decision analysis - Expected monetary value & Yes \\
\hline Decision Tree & May be used \\
\hline Monte Carlo simulations & Mostly no \\
\hline Network analysis & No \\
\hline $\begin{array}{c}\text { Program Evaluation and Review Technique } \\
\text { (PERT) }\end{array}$ & No \\
\hline Estimating relationships & No \\
\hline Rating schemes & Sensitivity analysis \\
\hline
\end{tabular}

Source: author's own study

\section{Predominant use in risk management}

Planning meetings are conducted to ensure the organization has a consistent vision in terms of the project's risk management. It does include risk methodology, roles and responsibilities, thresholds, timing, reporting formats, and approaches to tracking. These meetings focus on connecting key stakeholders on risk to conclude the risk practices to be pursued or the approach to be applied in pursuing them. [12]. This technique is recommended for all type of projects, but is the most effective in the initial risk planning stages. It can be widely used in EMS and in agriculture.

The technique of project templates involves the creation of various templates covering a specific scope that may pose a technical risk to the project or to specific processes. Each template considers the area that often poses a risk and then describes the methods (or gives examples) to avoid or control that risk. Many descriptions and solutions of risks have their roots in other projects. Project templates can be used for most projects, independently or in combination with other techniques. This method can be relevant for projects of any size at any stage of development. Since the technique sees project management as a complete process, the solutions presented reflect the interdependence of each part of the cycle [12]. This method may be used in EMS and for agriculture.

The risk practice methodology consists of several steps to be taken based on the structure and needs of the project in question. Most methodologies will outline clear steps in the process, form and practice. They will dictate (based on scale) the frequency with which these components are applied. They may be stored and made available in paper or electronic form, but they allow the organization of a common repository for both the forms and their filled-in equivalents. Since the risk practice methodology represents the accumulated practices of the project organization, it is usually used only in the most extreme circumstances. It applies as described for all projects where the methodology is already in use [12]. It may be used in EMS and risk management in agriculture, however it is time consuming and usually applicable in the most extreme circumstances.

A risk response matrix involves the initial and consistent performance of a number of specific tasks. The first step should be identification: all possible risks should be listed and defined. The next step is to assess the threat. Under this section, the previously selected probable problems are divided according to their threat to the company's design, life, health and finances. After that, possible actions that may be aimed at minimizing the damage should carefully be considered, therefore, this should be done in such a way that the problem does not occur at all. As an option, a scheme of reactions should be considered if the situation occurs. The last and longest stage is a performance check that includes the execution of actions that reduce risk and uncertainty. The results of such a matrix can be applied in the planning and decision-making process. As it presents a broad overview of the situation, it allows you to find out which decisions will be the right ones [12]. This method is also relatively inexpensive and applicable in small projects. It can be used widely in EMS and in agriculture. Table 4 presents all the discussed methods and their relevance for EMS in agriculture for family farms.

Table 4. Summary of methods

\begin{tabular}{|c|c|}
\hline Method & Useful for agriculture \\
\hline Project templates & Yes \\
\hline Risk practice methodology & Yes, it requires team discussion \\
\hline Risk response matrix & Yes, it requires team discussion \\
\hline Planning meetings & May be used \\
\hline \multicolumn{2}{|c|}{ Source: author's own study }
\end{tabular}




\section{Predominant use in monitoring and control of risks}

Checklists are a simple tool to control the correctness and/or the degree of completion of a project. This tool consists of a series of questions or issues concerning the project or its environment. The effectiveness of a checklist depends on its complexity. The more precise and detailed the questions it contains, the more effective it is, however, the longer the time it takes to prepare it. In risk management, the use of checklists at various stage of project implementation allows for a quick assessment, locations and causes of any risk [21]. This method has the advantage that it is applicable in a wide variety of situations, therefore it can be used also in EMS and agriculture.

Financial risk control allows managing risks within the company (retention, risk retention) or transferring them to the outside world. The simplest solution - risk retention in a company - does not involve additional initial expenditure, so the temptation to use the method is very strong. However, the entrepreneur must be aware that in the event of a natural disaster, the size of potential losses may exceed the financial capabilities of the company and result in its bankruptcy. The question of whether the entrepreneur had previously been aware of the potential risk and kept it inside as a result of a conscious decision (active attitude) or had no knowledge about the existence of a potential threat (passive attitude) comes to the background [22]. It does not find its application in EMS.

The performance tracking technique requires the use of a periodically updated technical risk assessment report. This report is based on activity-specific data but aims to provide an overall assessment of current trends and project status. The technique uses a set of standard technical indicators, which proved to be effective measures of technical parameters. Additionally, the analysts also develop particular technical indicators for the project. Each of them has clearly described performance projections and an array of warning criteria. This technique is most efficient when measurable and objective criteria are created. The method is best used to manage shortterm processes, but with minor adjustments, could be implemented on various types of projects [12]. It is applicable for EMS and for agriculture. It cannot be widely used in agriculture, because it is the best applicable to manage near-term projects.

Risk reviews and audits are an independent advisory and verification activity designed to improve the operational efficiency and added value of the organization, as well as risk management. An audit helps the organization to achieve its objectives through a systematic and methodical approach to assessing and improving the effectiveness of its risk management, control and management processes. Risk reviews and audits may take a variety of forms and formats, but they always contain enough common elements to be discussed together. The key to a robust risk review is to assume that it is a comprehensive risk review and not a review of a single isolated risk event. It is highly recommended for EMS and agriculture [23].

Table 5 presents all the discussed methods and their relevance for EMS in agriculture for family farms.

Table 5. Summary of methods

\begin{tabular}{|c|c|}
\hline Methods & Useful for agriculture \\
\hline Risk reviews and audits & Yes, requests second party \\
\hline Checklists & May be used \\
\hline Performance tracking & May be used, request developing indicators \\
\hline \multicolumn{2}{|c}{ Source: author's own study }
\end{tabular}

\section{Conclusion}

Based on practical experience, small and medium-sized enterprises (SMEs) may implement an effective EMS and gain a variety of benefits. However, the implementation of EMS can present various challenges. One of the advantages of implementing ISO 14001 is that it can be done in an organization of any type or size, since the requirements of an EMS are the same for all. However, the manner of implementing one will vary according to the size and activity of the organization [24].

An important element of the standard is the implementation of risk management in certified companies. Therefore, this article presents a review of risk management methods useful in family farms in agriculture, indicating those that seem to be the most useful for particular stages of risk management, and those that can be used in this process, but their usefulness seems to be limited.

It is worth noting that the list prepared by the author may constitute a basis for further implementation and testing of the proposed risk management methods by farmers. However, this process requires a conscious and methodical approach and the improvement of actions taken on the basis of current experience. 
In this case, it concerns both the identification of sources and risk factors and the usefulness of particular methods in the projects carried out. The key element of this process is to introduce changes in the adopted approach on the basis of previous experience and to introduce improvements and even more innovations. Moreover, it is also important that the farmer carefully identifies the type of risks influencing the project implemented by the farmer and the stage in which such risks may occur. In combination with the farmer's experience from previous projects and the knowledge accumulated in the literature in the identification of risk factors, these methods will give a chance to increase the probability of the end of the growing season without disturbing the balance.

The next step would be to conduct empirical studies on the actual level of implementation and use of risk management methods in family businesses that have implemented ISO14001. An important issue requiring further research is also the subjective assessment of users of these methods in terms of their usefulness in particular stages of the risk management process. An interesting direction would also be to conduct comparative research in EU countries on the most commonly used risk management methods in family farms.

\section{References}

[1] H. Aimin, "Uncertainty, Risk Aversion and Risk Management in Agriculture," Agric. Agric. Sci. Procedia, 2010.

[2] S. E. Harrington and G. R. Niehaus, "Risk Management and Insurance," J. Risk Insur., 2004.

[3] B. R. Gurjar and M. Mohan, "Environmental Risk Analysis: Problems and Perspectives in Different Countries," 13 Risk Heal. Saf. Environ. 95, vol. 13, no. 1, pp. 1-30, 2002.

[4] S. Riwthong, P. Schreinemachers, C. Grovermann, and T. Berger, "Agricultural commercialization: Risk perceptions, risk management and the role of pesticides in Thailand," Kasetsart J. Soc. Sci., 2017.

[5] J. Hardaker, B. M. H. Brian Ruud, and R. A. Jock, Coping with risk in agriculture. 2009.

[6] E. Bornhofen, T. G. Ramires, T. Bergonci, L. R. Nakamura, and A. J. Righetto, "Associations between global indices of risk management and agricultural development," Agric. Syst., 2019.

[7] R. Hölscher and U.-C. Rücker, "Die Finanzierung von Umweltrisiken," UmweltWirtschaftsForum, vol. 3, 4, 1999.

[8] C. Eipper, Die Bewertung des Umweltrisikos von Gewerbe- und In-dustriebetrieben - ein Verfahren zur praxisorientierten Durchfüh-rung von Umweltrisikoprüfungen auf der Grundlage von Risiko-studien für die Versicherungswirtschaft. Marburg: Tectum Verlag, 1994.

[9] K. Jajuga, Zarzadzanie ryzykiem. Warszawa: Wydawnictwo Naukowe PWN, 2007.

[10] C. P. Woodward and K. Singh, Managing Risk on Global Projects. Morgantown: AACE International Transactions, 1996.

[11] Project Management Institute, A Guide to the Project Management Body of Knowledge - PMBOK Guide. 2004.

[12] C. L. Pritchard, Risk Management: Concepts and Guidance. London: CRC Press, 2014.

[13] T. D. Carpenter, "Audit team brainstorming, fraud risk identification, and fraud risk assessment: Implications of SAS No. 99," Account. Rev., 2007.

[14] European Commission, "Eurostat Database," Roundwood removals under bark by type of ownership, 2016. .

[15] C. Markmann, I. L. Darkow, and H. von der Gracht, "A Delphi-based risk analysis - Identifying and assessing future challenges for supply chain security in a multi-stakeholder environment," Technol. Forecast. Soc. Change, 2013.

[16] C. Passarella, "Failure modes and effects analysis," Control, 2018.

[17] United States Department of Agriculture Risk Management Agency, "Swot Analysis: A tool for making better business decisions," Malayan Bank. Berhad SWOT Anal., 2008.

[18] P. K. Dey, "Project risk management using multiple criteria decision-making technique and decision tree analysis: A case study of Indian oil refinery," Production Planning and Control. 2012.

[19] J. Chinneck, "PERT for Project Planning and Scheduling," Pract. Optim. a Gentle Introd., 2006.

[20] H. C. Frey and S. R. Patil, "Identification and review of sensitivity analysis methods," in Risk Analysis, 2002.

[21] S. Marcelino-Sádaba, A. Pérez-Ezcurdia, A. M. Echeverría Lazcano, and P. Villanueva, "Project risk management methodology for small firms," Int. J. Proj. Manag., 2014.

[22] V. Aebi, G. Sabato, and M. Schmid, "Risk management, corporate governance, and bank performance in the financial crisis," J. Bank. Financ., 2012.

[23] K. Robson, C. Humphrey, R. Khalifa, and J. Jones, "Transforming audit technologies: Business risk audit methodologies and the audit field," Accounting, Organ. Soc., 2007.

[24] Susan L.K. Briggs, "Environmental management systems for SMEs a practical guide for SMEs," 2017.

https://doi.org/10.32933/Actalnnovations.33.6 •ISSN 2300-5599 • C 2019 RIC Pro-Akademia - CC BY 